\title{
A chemometric processing-factor-based approach to the determination of the fates of five pesticides during apple processing
}

\author{
Minmin Li ${ }^{\text {a, }}$, Yanan Liu ${ }^{\text {a, }}{ }^{1}$, Bei Fan ${ }^{a}$, Jia Lu ${ }^{\text {a }}$, Yan He ${ }^{a}$, Zhiqiang Kong ${ }^{a}$, Yulong Zhu ${ }^{\text {a }}$ \\ Qiu Jian ${ }^{\mathrm{b}}$, Fengzhong Wang ${ }^{\mathrm{a}, *}$
}

a Institute of Agro-products Processing Science and Technology, Chinese Academy of Agricultural Sciences/Key Laboratory of Agro-Products

Processing/Laboratory of Agro-products Quality Safety Risk Assessment, Ministry of Agriculture, Beijing, 100193, PR China

${ }^{\mathrm{b}}$ Institute for the Control of Agrochemicals, Chinese Ministry of Agriculture, Beijing, PR China

\section{A R T I C L E I N F O}

\section{Article history:}

Received 24 November 2014

Received in revised form

26 March 2015

Accepted 29 March 2015

Available online 8 April 2015

\section{Keywords:}

Apple

Processing factor

Chemometric approach

Pesticide residue

\begin{abstract}
A B S T R A C T
Food safety, especially with respect to pesticide-contaminated products, has received considerable attention in recent years. In this study, the effects of food processing steps on pesticide residues in apples were analyzed on the basis of processing factors (PFs) via a chemometric approach. Based on the PFs data, the removal efficiencies of beta-cypermethrin, chlorpyrifos, tebuconazole, acetamiprid, and carbendazim were optimized using a chemometric tool equipped with a central composite design (CCD). Several enzymatic treatment parameters that affect the removal efficiency of the processing procedure were investigated using a CCD screening design. Afterward, the identified significant factors were optimized to determine the optimum removal conditions. The results showed that the residue levels of these five pesticides in commercial juice may be further decreased using a reconstitution step. Apples with pesticide residue levels lower than the maximum residue levels can be assessed, and the resulting apple juice can be consumed directly.
\end{abstract}

(c) 2015 Elsevier Ltd. All rights reserved.

\section{Introduction}

The Environmental Working Group, a nonprofit advocacy agency, has released its list of the most pesticide-contaminated produce, and once again, apples top the Dirty Dozen: "An apple a day usually keeps the doctor away-unless it's ridden with pesticides" (http://www.huffingtonpost.com/2014/05/01/dirty-dozen2014-ewg-pesticides_n_5246989.html). According to the U.S. Environmental Protection Agency, pesticides have been linked to developmental problems in children (Ren et al., 2011), and may act as carcinogens or negatively affect the endocrine system. For apple products, safety and quality are among the most important factors influencing consumer choice today; not surprisingly, safety and quality are also the most important considerations of apple

\footnotetext{
Abbreviations: AJC, apple juice concentrate; CCD, central composite design; ECD, electron capture detector; LOD, limit of detection; PF, processing factor; RSM, response surface methodology; SPE, solid-phase extraction; SSE, signal suppression or enhancement; UHT, ultra-heat treatment; RSD, relative standard deviations.

* Corresponding author. Tel./fax: +86 1062815969.

E-mail address: wfengzhong@126.com (F. Wang).

1 Minmin Li and Yanan Liu contributed equally to this paper.
}

manufacturers and distributors, especially those that produce apple juice concentrate (AJC) (Pirsaheb, Fattahi, Pourhaghighat, Shamsipur, \& Sharafi, 2014). China, the largest apple producer in the world, accounts for almost $35 \%$ of total global apple production. China was also the No. 1 apple exporter in 2010, shipping approximately 1.12 million tons (Li, Qiu, Cai, \& Li, 2012).

Food processing includes the set of physical, chemical, and microbiological methods used to transmute raw agricultural commodities into food. Food processing also describes the process of transforming food into other forms for consumption by humans or animals (Kaushik, Satya, \& Naik, 2009; Kong, Shan, et al., 2012). The level and nature of pesticides in food may be changed during food processing. It is therefore of utmost importance for the apple industry to continue to seek out more effective methods to remove pesticides from products.

Pesticides can be roughly classified as hydrophilic (water soluble) or hydrophobic (water insoluble). It is well known that soluble pollutants on the surface of products are easily washed off with water, whereas insoluble pollutants persist on food and potentially threaten human health. In addition to insoluble surface pesticides, pesticide residues that are physically inside food products also persist after washing. Numerous studies have reported that food 
processing (including washing, peeling, boiling, and juicing) can largely reduce the levels of pesticide residues in food (Aguilera, Valverde, Camacho, Boulaid, \& Garcia-Fuentes, 2014; Han, Li, et al., 2013; Lopez-Fernandez, Rial-Otero, \& Simal-Gandara, 2013). Many studies have been carried out on the removal of pesticide residues from apples during home preparation and commercial processing (Han, Xu, et al., 2013; Kong, Shan, et al., 2012; Martin et al., 2013). However, no paper has reported on the fate of pesticide residues during the AJC manufacturing process. Hence, to obtain more insight into the effects of the process, we carried out a field experiment on apples, carrying out the AJC process.

Pesticide residue levels in fruits may change during processing. Ideally, a realistic risk assessment should consider the commodity, as much as possible, as consumed "at the table" (Claeys et al., 2011). In China, as in many other countries in the world, researchers evaluate the processing factors (PFs) of pesticides in food processing. The PFs assist in the dietary intake assessment of related pesticides in processed commodities (Amvrazi \& Albanis, 2008; BfR, 2010). However, the method used to assess the PFs of pesticides often fails to obtain accurate conclusions because it fails to account for all of the interactions among PFs. As a result, this method should be replaced by the more robust chemometric approach (Dejaegher \& Heyden, 2011). Chemometrics is the chemical discipline that applies statistical and mathematical methods based on mathematical logic to chemistry. Many chemometrics-based techniques such as multivariate experimental design and response surface methodology (RSM) have been employed to optimize analytical methods. The techniques allow for the efficient extraction of information from chemical data using fewer resources (Georgakopoulos et al., 2011; Paiga et al., 2012; Perez-Burgos et al., 2012). However, PFs can only provide information regarding the variation in pesticide residues resulting from food processing. Currently, there is no method that can simultaneously ensure the quality of processing and effectively assess the removal efficiency of pesticide residues. PFs combined with chemometrics constitute a good attempt to monitor and control pesticide residues. To our knowledge, there is a paucity of published research on the applications of chemometric methods to determine removal efficiencies. Furthermore, no studies have reported using chemometric approaches with PFs to optimize the removal efficiency of five pesticides.

Considering the aforementioned statements, the aims of this study were to evaluate the residue levels of five pesticides commonly found in apples: beta-cypermethrin, chlorpyrifos, tebuconazole, carbendazim, and acetamiprid. We also assessed the influence of commercial processes (washing, juicing, filtration, enzymatic treatment, sterilization, and concentration) on these pesticide residues. Another objective was to enhance the understanding of the effects of AJC processing on the PFs and to develop a chemometric approach (including experimental designs, RSMs, and desirability profiles) with the PFs to optimize the removal efficiency of the five pesticides. This was followed by UPLC-MS/MS and GC analysis for the simultaneous determination of the five pesticides in the apples and their by-products.

\section{Materials and methods}

\subsection{Field trials}

Trials were carried out in a commercial orchard located in Beijing, China. Chlorpyrifos, beta-cypermethrin, tebuconazole, acetamiprid, and carbendazim were chosen as the target pesticides due to their common application in conventional Fuji apple orchards. To ensure that sufficient target pesticides were deposited on the apples for the following processing studies, the five different commercial pesticide formulations were applied individually at a twofold higher dosage for a total of three sprayings at intervals of 7 days (Table 5). Random $60 \mathrm{~kg}$ apple samples were collected 3 days after the last treatment and placed in polyethylene bags. The apples were transported to the laboratory on the same day. At the laboratory, the apple samples were processed immediately, and all of the subsamples were stored frozen $\left(-20^{\circ} \mathrm{C}\right)$ until analysis.

\subsection{Materials}

Standard chlorpyrifos, beta-cypermethrin, tebuconazole, acetamiprid, and carbendazim materials (all purity > 97\%) were obtained from Dr. Ehrenstorfer GmbH (Augsburg, Germany). Acetone, $n$-hexane, acetonitrile, anhydrous magnesium sulfate, and sodium chloride were used for pesticide residue analysis and were purchased from Beijing Chemical and Reagent (Beijing, China). Chromatography grade acetonitrile was obtained from Honeywell International Inc. (New Jersey, USA). Primary secondary amine and Florisil (1000 mg/6 mL) solid-phase extraction (SPE) columns were purchased from Agela Technologies (Tianjin, China). Water was purified $\left(18.0 \mathrm{M} \Omega \mathrm{cm}\right.$ at $25{ }^{\circ} \mathrm{C}$ ) using an ultrapure purification system (Millipore, MA, USA).

\subsection{Sample preparation}

Fig. 1 shows the processing flow diagram. The processing conditions were established in accordance with industrial practices corresponding as closely as possible to the actual conditions. In general, the production of AJC includes seven steps: washing, juicing, primary filtration, enzymatic treatment, secondary filtration, sterilization, and concentration. In the current study, samples (washed apples, squeezed juice, apple pomace, filtered juice, clarified juice, sterilized juice, and concentrated apple juice) from the different processing stages were collected to determine and investigate the variation in pesticide residues during the processing procedure.

The obtained raw apples ( $20 \mathrm{~kg}$ ) were washed with running tap water $\left(10 \mathrm{~L} \mathrm{~min}^{-1}, 25^{\circ} \mathrm{C}\right)$ by shaking three times for $10 \mathrm{~min}$. An automatic juice extractor (Guangzhou XuZhong Food Machinery Co., Ltd., China) was fed with apples (which were cut into quarters). This process produced squeezed juice and pomace. The squeezed juice was filtered through a diatomaceous earth filter. Then, the primary filtered juice was treated with amylase $(0.1 \%, w / w)$ and pectinase $(0.1 \%, w / w)$ (Jiangsu Ruiyang BioTech Co., Ltd., China) at $50{ }^{\circ} \mathrm{C}$ for $1.5 \mathrm{~h}$. These enzymes break down the starch and pectic substances in apple juice, producing a fine particulate suspension. The enzyme-treated juice was filtered using an FT15 Disc Bowl Centrifuge (Armfield Ltd., England) at a speed of $4000 \mathrm{rpm}$. The juice was subjected to sterilization at $140{ }^{\circ} \mathrm{C}$ for approximately $10 \mathrm{~s}$ through ultra-heat treatment (UHT) (Shanghai Triowin Automation Machinery Co., Ltd., China). An HZ-TNG-30L multifunctional extraction and concentration system (Beijing Nainuo Biological Technology Co., Ltd., China) was used with the primary temperature setting at $60^{\circ} \mathrm{C}$ for $30 \mathrm{~s}$ to reach the final Brix of $85^{\circ} \mathrm{C}$ for this study.

\subsection{Extraction and analysis of pesticides}

\subsubsection{Analysis of chlorpyrifos and beta-cypermethrin by GC}

The analytical method was previously described in Kong, Shan, et al. (2012). An Agilent GC 7890A (Agilent Technologies, USA) equipped with an electron capture detector (ECD) was used. Briefly, beta-cypermethrin was extracted with acetonitrile from the homogenized samples (10 g apple or $20 \mathrm{~mL}$ apple juice). The betacypermethrin residue was analyzed by GC-ECD. All of the GC parameters for the beta-cypermethrin analyses are listed in Table $1 \mathrm{a}$. 
Table 1

GC and UPLC-MS/MS parameters for beta-cypermethrin, chlorpyrifos, tebuconazole, acetamiprid, and carbendazim analysis.

\begin{tabular}{|c|c|c|c|c|c|c|c|c|c|c|c|}
\hline \multicolumn{12}{|c|}{ a) Gas-ECD parameters } \\
\hline \multicolumn{2}{|l|}{ Gas parameters } & \multicolumn{2}{|c|}{ Column } & \multicolumn{3}{|l|}{ Carrier gas } & Injection volume & \multicolumn{4}{|c|}{ Oven temperature } \\
\hline \multicolumn{2}{|c|}{ ECD (Beta-cypermethrin) } & \multicolumn{2}{|c|}{$\begin{array}{l}\text { HP-5 (30 m*0.32 mm I.D., } \\
0.25 \mu \mathrm{m} \text { film thickness) }\end{array}$} & \multicolumn{3}{|c|}{$\begin{array}{l}\text { Ultra-pure quality } \\
\text { nitrogen (purity 99.999\%) }\end{array}$} & $1.0 \mu \mathrm{L}$ & \multicolumn{4}{|c|}{$\begin{array}{l}70{ }^{\circ} \mathrm{C} \text { for } 1 \mathrm{~min} \text { and ramped to } 280{ }^{\circ} \mathrm{C} \text { at } 20^{\circ} \mathrm{C} / \mathrm{min} \text {, } \\
\text { and held for } 5 \mathrm{~min}\end{array}$} \\
\hline \multicolumn{12}{|c|}{ b) Parameters of mass spectrometry } \\
\hline \multicolumn{2}{|l|}{ Ionization mode } & Capillary (kV) & \multicolumn{2}{|c|}{ Extractor (V) } & \multicolumn{2}{|c|}{$\begin{array}{l}\text { Source } \\
\text { temperature }\left({ }^{\circ} \mathrm{C}\right)\end{array}$} & \multicolumn{2}{|c|}{$\begin{array}{l}\text { Desolvation } \\
\text { temperature }\left({ }^{\circ} \mathrm{C}\right)\end{array}$} & $\begin{array}{l}\text { Cone gas } \\
\text { flow }(\mathrm{L} / \mathrm{Hr})\end{array}$ & & $\begin{array}{l}\text { Desolvation gas } \\
\text { flow }(\mathrm{L} / \mathrm{Hr})\end{array}$ \\
\hline $\mathrm{ESI}^{+}$ & 3.0 & & 1.0 & & 120 & & 350 & & & 50 & \\
\hline \multicolumn{12}{|c|}{ c) UPLC-MS/MS parameters } \\
\hline Compounds & $\begin{array}{l}\text { Molecular } \\
\text { formula }\end{array}$ & $\begin{array}{l}\text { Molecular } \\
\text { weight }\end{array}$ & $\begin{array}{l}\text { Precursor } \\
\text { ion }(m / z)\end{array}$ & $\begin{array}{l}\text { Qualifier } \\
\text { ion }(m / z)\end{array}$ & $\begin{array}{l}\mathrm{Q} / \mathrm{q} \\
\text { ratio }^{\mathrm{a}}\end{array}$ & $\begin{array}{l}\text { Cone } \\
\text { voltage }(\mathrm{V})\end{array}$ & $\begin{array}{l}\text { Collision } \\
\text { energy }(\mathrm{V})\end{array}$ & $\begin{array}{l}\text { Relative collision } \\
\text { energy (\%) }\end{array}$ & $\begin{array}{l}\text { Dwell } \\
\text { time }(s)\end{array}$ & $\mathrm{RT}(\mathrm{min})$ & $\mathrm{Q} / \mathrm{q}$ ratio $^{\mathrm{b}}$ \\
\hline Chlorpyrifos & $\mathrm{C}_{9} \mathrm{H}_{11} \mathrm{Cl}_{3} \mathrm{NO}_{3} \mathrm{PS}$ & 350.5 & 352 & $\begin{array}{r}97 \\
200\end{array}$ & Q & 30 & $\begin{array}{l}30 \\
30\end{array}$ & $\begin{array}{l}33.3 \\
33.3\end{array}$ & 0.10 & 2.80 & $\begin{array}{l}- \\
3.7\end{array}$ \\
\hline Tebuconazole & $\mathrm{C}_{16} \mathrm{H}_{22} \mathrm{ClN}_{3} \mathrm{O}$ & 307.82 & 308 & $\begin{array}{r}70 \\
125\end{array}$ & $\mathrm{Q}$ & 30 & $\begin{array}{l}25 \\
15\end{array}$ & $\begin{array}{l}27.8 \\
16.7\end{array}$ & 0.10 & 1.23 & $-\overline{2.6}$ \\
\hline Acetamiprid & $\mathrm{C}_{10} \mathrm{H}_{11} \mathrm{ClN}_{4}$ & 222.67 & 223 & $\begin{array}{r}126 \\
56\end{array}$ & $\begin{array}{l}\mathrm{Q} \\
\mathrm{q}\end{array}$ & 40 & $\begin{array}{l}20 \\
20\end{array}$ & $\begin{array}{l}22.2 \\
22.2\end{array}$ & 0.10 & 1.90 & $\begin{array}{l}- \\
7.4\end{array}$ \\
\hline Carbendazim & $\mathrm{C}_{9} \mathrm{H}_{9} \mathrm{~N}_{3} \mathrm{O}_{2}$ & 191.2 & 192 & $\begin{array}{l}160 \\
132\end{array}$ & $\mathrm{Q}$ & 33 & $\begin{array}{l}28 \\
18\end{array}$ & $\begin{array}{l}31.1 \\
20.0\end{array}$ & 0.10 & 2.00 & $\overline{6.6}$ \\
\hline
\end{tabular}

${ }^{\text {a }} \mathrm{Q}$ is quantification ion transition and $\mathrm{q}$ is confirmation ion transition.

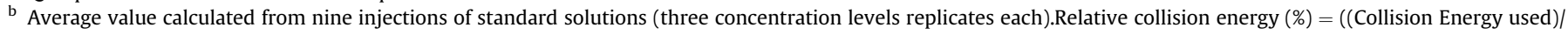
(Collision energy max))*100.

2.4.2. Analysis of chlorpyrifos, tebuconazole, acetamiprid, and carbendazim by UPLC-MS/MS

The analytical method used to analyze the pesticides was based on the QuEChERS method. Chromatographic separation was carried out on a Waters Acquity UPLC binary solvent manager equipped with a Waters Acquity UPLC BEH $\mathrm{C}_{18}$ column $(2.1 \mathrm{~mm} \times 50 \mathrm{~mm}$, $1.7 \mu \mathrm{m}$ particle size) (Milford, MA, USA). The UPLC MS-MS conditions were optimized individually for each target compound and

Table 2

Linear regression parameters of the calibration curves for the five pesticides in pure solvent and seven matrices for $0.005-2.0 \mathrm{mg}^{\mathrm{kg}} \mathrm{g}^{-1}$.

\begin{tabular}{|c|c|c|c|c|c|c|c|}
\hline Compounds & Matrix & Regression equation & $\mathrm{R}^{2}$ & Slope ratio & Matrix effect (\%) & $\operatorname{LODs}\left(\mu \mathrm{gg}^{-1}\right)$ & LOQs $\left(\mu \mathrm{g} \mathrm{kg}^{-1}\right)$ \\
\hline \multirow[t]{7}{*}{ Beta-Cypermethrin } & $n$-hexane & $y=1038 x+64.371$ & 0.9998 & - & - & - & - \\
\hline & Raw apples & $y=1120 x+76.771$ & 0.9995 & 1.2 & -19.3 & 3.1 & 9.4 \\
\hline & Squeezed juice & $y=986 x+72.264$ & 0.9993 & 1.1 & -12.3 & 2.2 & 6.5 \\
\hline & Squeezed pomace & $y=1241 x+54.174$ & 0.9998 & 0.8 & 15.8 & 2.1 & 6.2 \\
\hline & Filtrated juice & $y=1935 x-75.761$ & 0.9991 & 1.2 & -17.6 & 2.9 & 8.8 \\
\hline & Clarified juice & $y=993 x+56.295$ & 0.9991 & 0.9 & 11.5 & 2.7 & 8.2 \\
\hline & AJC & $y=1012 x+51.910$ & 0.9982 & 0.8 & 19.4 & 1.8 & 5.3 \\
\hline \multirow[t]{7}{*}{ Chlorpyrifos } & Methanol & $y=130989 x-1187.3$ & 0.9997 & - & - & - & - \\
\hline & Raw apples & $y=136840 x+993.5$ & 0.9983 & 0.8 & -16.3 & 0.6 & 1.9 \\
\hline & Squeezed juice & $y=121341 x+1342.1$ & 0.9989 & 1.1 & -13.0 & 0.9 & 1.5 \\
\hline & Squeezed pomace & $y=163781 x+988.9$ & 0.9995 & 0.8 & 16.7 & 0.7 & 1.9 \\
\hline & Filtrated juice & $y=110036 x-1432.2$ & 0.9997 & 1.2 & -20.6 & 0.9 & 2.5 \\
\hline & Clarified juice & $y=176584 x+1003.4$ & 0.9996 & 0.8 & 15.5 & 0.6 & 2.0 \\
\hline & $\mathrm{AJC}$ & $y=1374561 x+970.1$ & 0.9993 & 0.8 & 18.3 & 0.4 & 1.4 \\
\hline \multirow[t]{7}{*}{ Tebuconazole } & Methanol & $y=89525 x+4810.3$ & 0.9994 & - & - & - & - \\
\hline & Raw apples & $y=96552 x+5430.9$ & 0.9995 & 1.1 & -12.9 & 0.5 & 0.9 \\
\hline & Squeezed juice & $y=86954 x+5802.7$ & 0.9995 & 1.2 & -20.6 & 0.9 & 2.9 \\
\hline & Squeezed pomace & $y=78923 x+3997.8$ & 0.9988 & 0.8 & 16.8 & 0.7 & 1.9 \\
\hline & Filtrated juice & $y=77639 x-5663.2$ & 0.9994 & 1.2 & -17.7 & 0.6 & 1.7 \\
\hline & Clarified juice & $y=89931 x+4031.3$ & 0.9989 & 0.8 & 16.2 & 0.9 & 2.7 \\
\hline & AJC & $y=93514 x+3765.5$ & 0.9988 & 0.8 & 21.7 & 0.3 & 1.1 \\
\hline \multirow[t]{7}{*}{ Acetamiprid } & Methanol & $y=5210.3 x-58.195$ & 0.9993 & - & - & - & - \\
\hline & Raw apples & $y=5334.4 x+80.194$ & 0.9993 & 1.4 & -37.8 & 0.6 & 1.8 \\
\hline & Squeezed juice & $y=6011.2 x+75.846$ & 0.9991 & 1.3 & -30.3 & 0.3 & 0.8 \\
\hline & Squeezed pomace & $y=5003.1 x+42.126$ & 0.9989 & 0.7 & 27.6 & 0.5 & 1.4 \\
\hline & Filtrated juice & $y=5541 x-84.920$ & 0.9994 & 1.5 & -45.9 & 0.8 & 2.3 \\
\hline & Clarified juice & $y=5994.2 x+47.037$ & 0.9981 & 0.8 & 19.2 & 0.6 & 1.9 \\
\hline & $\mathrm{AJC}$ & $y=6123.2 x+40.141$ & 0.9989 & 0.7 & 31.0 & 0.2 & 0.7 \\
\hline \multirow[t]{7}{*}{ Carbendazim } & Methanol & $y=198107 x+9481.5$ & 0.9995 & - & - & - & - \\
\hline & Raw apples & $y=192411 x+11096.4$ & 0.9994 & 1.2 & -17.0 & 0.5 & 1.6 \\
\hline & Squeezed juice & $y=124250 x+10783.7$ & 0.9992 & 1.1 & -13.7 & 0.9 & 2.8 \\
\hline & Squeezed pomace & $y=154363 x+8965.8$ & 0.9990 & 0.9 & 5.4 & 0.6 & 1.9 \\
\hline & Filtrated juice & $y=198128 x-10023.1$ & 0.9989 & 1.1 & -5.7 & 0.6 & 1.7 \\
\hline & Clarified juice & $y=154122 x+7997.3$ & 0.9991 & 0.8 & 15.6 & 0.7 & 2.2 \\
\hline & AJC & $y=133013 x+7462.5$ & 0.9993 & 0.8 & 21.2 & 0.3 & 1.0 \\
\hline
\end{tabular}

Matrix effect $(\%)=(1-($ slope matrix/slope solvent $)) \times 100$ Slope ratio $=$ matrix/methanol (hexane). 
Table 3

Recovery and RSD values obtained for the five pesticides in various matrixes at three spiking levels.

\begin{tabular}{|c|c|c|c|c|c|c|c|c|c|c|c|c|c|c|c|c|}
\hline \multirow[t]{2}{*}{ Sample } & \multirow{2}{*}{$\begin{array}{l}\text { Fortification } \\
\left(\mathrm{mg} \mathrm{kg}^{-1}\right)\end{array}$} & \multicolumn{3}{|c|}{ Beta-Cypermethrin } & \multicolumn{3}{|c|}{ Chlorpyrifos } & \multicolumn{3}{|c|}{ Tebuconazole } & \multicolumn{3}{|c|}{ Acetamiprid } & \multicolumn{3}{|c|}{ Carbendazim } \\
\hline & & Recovery & $\mathrm{RSD}^{\mathrm{a}}$ & $\mathrm{RSD}^{\mathrm{b}}$ & Recovery & $\mathrm{RSD}^{\mathrm{a}}$ & $\mathrm{RSD}^{\mathrm{b}}$ & Recovery & $\mathrm{RSD}^{\mathrm{a}}$ & $\mathrm{RSD}^{\mathrm{b}}$ & Recovery & $\mathrm{RSD}^{\mathrm{a}}$ & $\mathrm{RSD}^{\mathrm{b}}$ & Recovery & $\mathrm{RSD}^{\mathrm{a}}$ & $\mathrm{RSD}^{\mathrm{b}}$ \\
\hline \multirow[t]{3}{*}{ Raw apples } & 1 & 88.0 & 9.1 & 7.1 & 90.4 & 3.7 & 6.7 & 89.9 & 5.7 & 10.3 & 92.3 & 8.7 & 3.7 & 93.5 & 3.5 & 11.6 \\
\hline & 0.1 & 81.8 & 8.3 & 9.6 & 85.5 & 3.3 & 4.5 & 90.1 & 9.1 & 4.5 & 84.4 & 8.9 & 5.4 & 86.9 & 4.2 & 4.5 \\
\hline & 0.01 & 87.5 & 2.9 & 9.4 & 79.8 & 6.5 & 9.8 & 86.3 & 9.5 & 9.6 & 80.2 & 9.2 & 8.5 & 79.9 & 5.5 & 4.9 \\
\hline \multirow{3}{*}{$\begin{array}{l}\text { Squeezed } \\
\text { juice }\end{array}$} & 1 & 116.3 & 7.8 & 8.6 & 93.6 & 3.5 & 5.4 & 91.5 & 6.6 & 7.4 & 86.5 & 6.4 & 3.8 & 96.5 & 1.6 & 5.4 \\
\hline & 0.1 & 103.9 & 8.6 & 9.4 & 104.6 & 3.8 & 6.9 & 82.3 & 6.9 & 7.3 & 99.6 & 5.5 & 3.5 & 104.8 & 6.3 & 6.9 \\
\hline & 0.01 & 96.3 & 9.9 & 10.1 & 96.7 & 8.5 & 10.3 & 97.2 & 7.9 & 10.1 & 102.3 & 6.1 & 6.4 & 102.3 & 5.5 & 10.1 \\
\hline \multirow{3}{*}{$\begin{array}{l}\text { Squeezed } \\
\text { pomace }\end{array}$} & 1 & 109.5 & 3.4 & 4.5 & 91.5 & 4.8 & 7.9 & 84.6 & 3.7 & 4.7 & 91.5 & 9.7 & 3.2 & 97.8 & 7.5 & 6.0 \\
\hline & 0.1 & 95.3 & 6.5 & 9.2 & 97.6 & 4.3 & 5.2 & 98.6 & 2.4 & 3.2 & 97.5 & 1.5 & 7.3 & 96.7 & 3.1 & 5.2 \\
\hline & 0.01 & 105.9 & 7.3 & 9.1 & 95.3 & 8.3 & 9.7 & 94.6 & 6.8 & 10.2 & 95.3 & 3.7 & 4.0 & 94.5 & 2.5 & 9.7 \\
\hline \multirow{3}{*}{$\begin{array}{l}\text { Filtrated } \\
\text { juice }\end{array}$} & 1 & 88.9 & 7.2 & 10.8 & 89.1 & 5.5 & 9.1 & 89.1 & 5.5 & 5.9 & 78.9 & 6.4 & 7.2 & 88.9 & 4.8 & 9.1 \\
\hline & 0.1 & 106.3 & 6.3 & 6.5 & 102.0 & 3.2 & 6.5 & 101.9 & 3.2 & 4.3 & 96.2 & 7.3 & 5.5 & 87.5 & 6.6 & 6.5 \\
\hline & 0.01 & 91.4 & 6.2 & 8.1 & 89.1 & 7.3 & 10.4 & 83.7 & 5.8 & 7.0 & 86.7 & 8.1 & 4.1 & 86.3 & 8.7 & 9.0 \\
\hline \multirow{3}{*}{$\begin{array}{l}\text { Clarified } \\
\text { juice }\end{array}$} & 1 & 92.1 & 7.4 & 7.5 & 89.1 & 3.0 & 3.4 & 107.0 & 3.9 & 4.6 & 89.5 & 6.5 & 9.7 & 84.9 & 2.9 & 3.4 \\
\hline & 0.1 & 98.9 & 5.8 & 6.3 & 97.4 & 3.0 & 3.2 & 108.4 & 5.6 & 6.0 & 96.5 & 5.3 & 7.6 & 98.3 & 3.0 & 3.2 \\
\hline & 0.01 & 100.9 & 7.0 & 8.9 & 105.3 & 4.4 & 5.4 & 79.5 & 6.3 & 7.7 & 104.5 & 3.6 & 3.4 & 102.5 & 4.4 & 5.4 \\
\hline \multirow[t]{3}{*}{$\mathrm{AJC}$} & 1 & 81.0 & 7.8 & 4.1 & 85.2 & 3.4 & 9.2 & 102.1 & 9.0 & 5.4 & 87.4 & 7.9 & 5.1 & 97.2 & 8.8 & 9.2 \\
\hline & 0.1 & 83.0 & 9.6 & 6.4 & 100.3 & 6.6 & 9.8 & 89.2 & 4.5 & 5.6 & 95.4 & 5.8 & 11.3 & 98.6 & 2.1 & 7.6 \\
\hline & 0.01 & 84.0 & 8.7 & 5.6 & 90.6 & 6.7 & 9.7 & 81.2 & 6.5 & 6.1 & 83.0 & 9.1 & 4.1 & 89.8 & 6.8 & 10.3 \\
\hline
\end{tabular}

a Intra-day $(\mathrm{n}=5)$.

b Inter-day $(\mathrm{n}=15)$.

Table 4

The processing factors (PFs) for five pesticides after different processes.

\begin{tabular}{|c|c|c|c|c|c|}
\hline \multirow[t]{2}{*}{ Processing } & \multicolumn{5}{|l|}{ Processing factor } \\
\hline & Beta-cypermethrin & Chlorpyrifos & Tebuconazole & Acetamiprid & Carbendazim \\
\hline Washing & 0.94 & 0.79 & 0.88 & 0.34 & 0.53 \\
\hline Juicing & 0.17 & 0.19 & 0.33 & 0.91 & 0.20 \\
\hline Primary filtrating & 0.43 & 0.83 & 0.48 & 0.82 & 0.83 \\
\hline Enzymatic treatment & 0.68 & 0.93 & 0.55 & 0.89 & 0.31 \\
\hline Secondary filtrating & 0.81 & 0.92 & 0.96 & 0.96 & 0.78 \\
\hline Sterilizing & 0.49 & 0.34 & 0.81 & 0.87 & 0.78 \\
\hline Concentration & 1.8 & 2.3 & 4.5 & 4.8 & 1.7 \\
\hline
\end{tabular}

are listed in Table 1b and c. GC-ECD and UPLC-MS/MS chromatograms of an apple sample spiked at $0.1 \mathrm{mg} \mathrm{kg}^{-1}$ are shown in Fig. 2.

\subsection{Removal experimental design}

To evaluate and optimize the parameters that affect pesticide removal efficiency during the production of apple juice concentrates, a central composite design (CCD) was used to evaluate the identified significant variables and to determine the optimal factor levels for each of the responses. A CCD consists of a two-level factorial design ( $2 f$ ) with ( $2 f$ ) star points, where $f$ is the number of variables, and at least one central point $\left(N_{0}\right)$ selected to establish the rotatability or orthogonality of the experimental design, in order to fit quadratic polynomials. The central points are often repeated to estimate the experimental error (pure error) (Khodadousta, Ghaedia, \& Hadjmohammadib, 2013). Thus, the total number of the experimental points needed $(N)$ is determined by the following equation: $N=2 f+2 f+N_{0}$. Finally, Derringer's desirability function is used to optimize the experimental conditions to obtain desirable pesticide removal yields.
The experimental matrix designs were implemented, and the results were evaluated using the StatSoft Statistica 8.0 computer program.

\section{Results and discussion}

The study of the fate of five pesticides during the simulated industrial processing of AJC is described. The PFs for selected pesticides during different processing steps were calculated, which are necessary to refine the risk assessment of frequently detected pesticides.

\subsection{Verification of analytical procedure}

The limits of detection (LODs) for chlorpyrifos, betacypermethrin, tebuconazole, acetamiprid, and carbendazim were considered as the concentrations that produced signal-to-noise (S/ $\mathrm{N})$ ratios of 3. The LODs were in the range $0.2-3.1 \mu \mathrm{g} \mathrm{kg}^{-1}$ (Table 2), and were less than or equal to those obtained by other authors (Gomez-Perez, Plaza-Bolanos, Romero-Gonzalez, Martinez-Vidal, \&

Table 5

Details of field trials and main physical and chemical properties of the studied pesticides.

\begin{tabular}{|c|c|c|c|c|}
\hline Pesiticide & Property & Twofold higher dosage $\mathrm{g}$ (a.i.) ha ${ }^{-1}$ & $\log \operatorname{Kow}\left(20^{\circ} \mathrm{C}\right)$ & Water-soluble $\left(\mathrm{mg} \mathrm{L}^{-1}, 20^{\circ} \mathrm{C}\right)$ \\
\hline Beta-cypermethrin & non-absorption & 75 & 4.7 & 0.051 \\
\hline Chlorpyrifos & non-absorption & 1320 & 4.7 & 1.05 \\
\hline Tebuconazole & absorption & 400 & 3.7 & 36 \\
\hline Acetamiprid & absorption & 3 & 0.8 & 2950 \\
\hline Carbendazim & absorption & 2000 & 1.5 & 8.0 \\
\hline
\end{tabular}




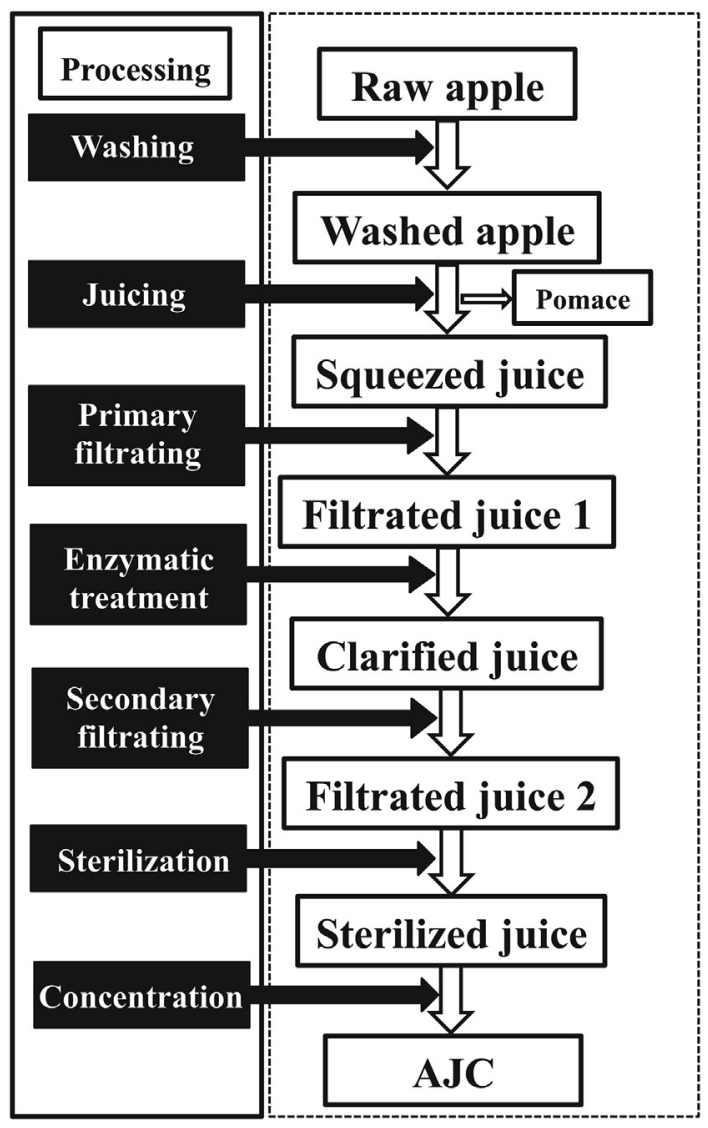

Fig. 1. Scheme for apple juice concentrate (AJC) processing used in this study and sampling points.

Garrido-Frenich, 2012; Zhang et al., 2012). The LOD results obtained by GC-ECD were higher than those by UPLC-MS/MS, probably because of the higher selectivity and better sensitivity of the mass spectrometer. The linearity for both methods was evaluated in the range $0.005-2.0 \mathrm{mg} \mathrm{kg}^{-1}$. In all cases, good linearity was achieved with correlation coefficients exceeding 0.9981. Recoveries during the analysis of the apples and apple production were $78.9-116.3 \%$ at three concentration levels. In general, the relative standard deviations (RSD) ${ }^{\mathrm{a}}$ and $\mathrm{RSD}^{\mathrm{b}}$ for the proposed method ranged from 1.5 to $9.9 \%$ and $3.2-11.6 \%$, respectively, which were within the range expected for residue analysis as per the recommendations in Document No. SANCO/10684/2009 (European Commission, 2009) (Table 3). The results of the recovery studies demonstrated that the dispersive solid-phase extraction clean-up (dSPE) of the UPLC-MS/ MS method achieved satisfactory trueness, precision, and sensitivity for pesticide analysis in foodstuffs such as apple matrices.

\subsection{Matrix effects}

The presence of matrix components can affect the ionization of the target compounds when ESI is used (Dams, Huestis, Lambert, \& Murphy, 2003). Depending on the decrease or increase in the percentage of the slope, different matrix effects could be observed: changes between $-20 \%$ and $+20 \%$ was considered as mild signal suppression or enhancement effects; those between $-50 \%$ and $+50 \%$ was considered medium effects; and strong signal suppression or enhancement effects were assigned below $-50 \%$ or above $+50 \%$.

The data in Table 2 indicate that obvious signal suppression or enhancement differences were observed for the five analytes in the seven matrices, as the slope ratios of matrix/n-hexane or methanol were in the range $0.7-1.5$, and the slope values were between $-45.9 \%$ and $+31.0 \%$. For beta-cypermethrin, chlorpyrifos, tebuconazole, and carbendazim, the raw apples, squeezed juice, squeezed pomace, filtered juice, clarified juice, and AJC matrices presented soft signal suppression and enhancement effects (SSE slope $=0.8-1.2)$. In some cases, enhancement appeared for the AJC matrices (SSE slope $=0.7-0.8$ ). However, for acetamiprid, the matrices presented medium signal suppression and enhancement effects (SSE slope $=0.7-1.5$ ). Generally, the suppression or enhancement effects originate from the insufficient removal of endogenous compounds such as phospholipids, fatty acids, saccharides, phenols, and pigments. However, the real origins and mechanisms underlying these matrix effects are still not fully understood and should be further investigated. Therefore, the use of
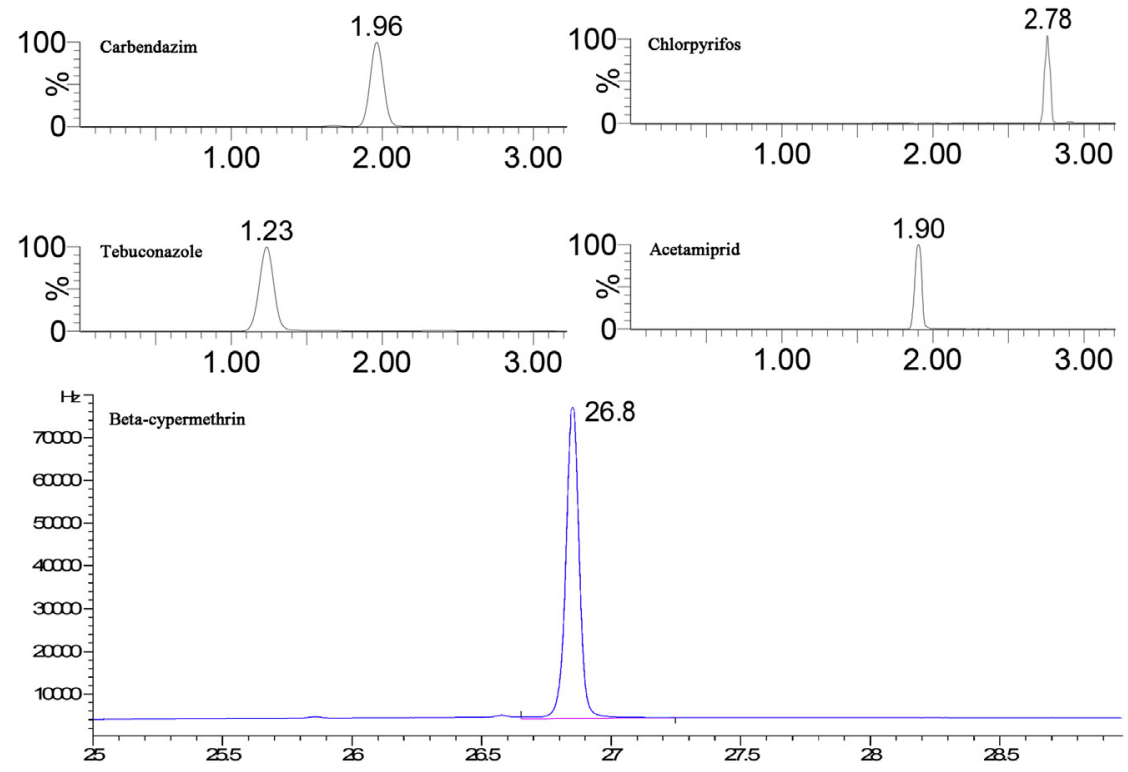

Fig. 2. GC-ECD and UPLC-MS/MS chromatograms of an apple sample spiked at $0.1 \mathrm{mg} \mathrm{kg} \mathrm{kg}^{-1}$. 
matrix-matched calibration solutions is necessary to compensate for errors associated with matrix-induced suppression or enhancement effects in the new dSPE method. In this study, calibrations were performed for the five pesticides using external matrix-matched standards to eliminate matrix effects and obtain realistic results for all samples.

\subsection{Processing factors}

The Joint FAO/WHO Meeting on Pesticide Residues (JMPR) evaluates data on residue behavior when significant residues occur in plant or plant products that are processed into food. Based on the effect on residue levels and the disposition of the residues in the various processed products, processing factors are calculated and considered by the JMPR (FAO/WHO, 2006) and the Organization for Economic Co-operation and Development (OECD, 2008) as follows:

PFs $=$

residue level in processed commodity

residue level in the RAW or commodity to be processed

A PF value of $<1$ (=reduction factor) indicates a reduction in the residue in the processed commodity, whereas a value $>1$ (=concentration factor) indicates a concentration effect of the processing procedures (Timme \& Walz-Tylla, 2004).

Washing is the most common form of processing, and is a preliminary step in both the household and commercial preparation of apples (Kaushik et al., 2009). Several studies have examined the effectiveness of washing to remove pesticide residues in fruits and vegetables (Aguilera et al., 2014; Kong, Dong, et al., 2012; Ling et al., 2011). As presented in Table 4, we can see that intensively washing the apples did not significantly reduce the residue of betacypermethrin, whereas the reductions in the levels of acetamiprid and carbendazim residues were higher. After the washing process, the mean losses of chlorpyrifos, beta-cypermethrin, tebuconazole, acetamiprid and carbendazim were $21.3 \%, 6.2 \%$, $11.9 \%, 66.2 \%$, and $47.3 \%$, respectively (Fig. 3). These results can be rationalized by the high octanol/water partition coefficients and water solubilities of the pesticides. Additionally, the washing procedure and the physicochemical properties of the pesticides and the crop skin also affect the elimination of pesticides (Aguilera et al., 2014).

Next, the apple was cut into quarters and juiced with the pomace removed. Only $17.4-32.7 \%$ of the total residues were retained in the squeezed juice (with the exception of acetamiprid, which was highly distributed in the juice). Hence, the reduction of Beta-cypermethrin, chlorpyrifos, tebuconazole, and carbendazim after juicing might be due to the removal of the apple pomace (Kaushik et al., 2009). Holland, Hamilton, Ohlin, and Skidmore (1994) observed that the pomace often retains a substantial proportion of lipophilic residues. The pomace was juiced a second time. Comparing the juices from the first and second squeezings, our study indicates that pesticide reduction by juicing is inversely related to water solubility (Fig. 4). For chlorpyrifos (water solubility $\left.1.05 \mathrm{mg} \mathrm{kg}^{-1}\right)$, beta-cypermethrin $\left(0.051 \mathrm{mg} \mathrm{kg}^{-1}\right)$, tebuconazole (36.0 mg kg-1), acetamiprid (2950.0 mg kg-1), and carbendazim ( $8.0 \mathrm{mg} \mathrm{kg}^{-1}$ ), the content reduction from juicing increases as the water solubility of the pesticide decreases (Table 5). This range of values is similar to that obtained by Burchat et al. (1998) in a previous study on the effect of home processing on the level of pesticides in different fruits and vegetables. However, in other juicing studies, the pesticide reduction rates have been independent of water solubility (Li, Jiao, et al., 2012; Li, Qu, et al., 2012).

After juicing, the squeezed juice was filtered through a diatomaceous earth filter. Fig. 3 shows that the primary filtering process produced a $16.5-57.0 \%$ reduction of the five pesticides. Fernandez, Oliva, Barba, and Camara (2005) and Oliva, Paya, Camara, and Barba (2007) investigated the effects of clarification agents on the removal of pesticide residues and found that filtration was not an effective step in the elimination of residues from wine. To clarify the juice, the primary filtered juice was further processed with amylase and pectinase, and the enzymatically treated juice was secondarily filtered. As shown in Fig. 3, enzymatic treatment resulted in a decrease in the levels of beta-cypermethrin, chlorpyrifos, tebuconazole, acetamiprid, and carbendazim by $31.9 \%, 7.3 \%, 45.4 \%, 11.5 \%$, and $68.6 \%$, respectively.

\subsection{Removal efficiency design}

To remove more of the carbendazim residue and further optimize fruit juice clarification, CCD was used to investigate the factors that influence the enzymatic treatment. In the CCD step, the experiments were conducted randomly to minimize the effect of uncontrolled variables. In this research, the mathematical relationship of the responses to the variables could be fitted by a quadratic model, which is expressed by the following polynomial equation: $y=b_{0}+b_{1} X_{1}+b_{2} X_{2}+b_{3} X_{3}+b_{12} X_{1} X_{2}+b_{13} X_{1}$ $X_{3}+b_{23} X_{2} X_{3}+b_{11} X_{2}+b_{22} X_{2}+b_{33} X_{3}$, where $y$ is the response, and $X_{1}, X_{2}$, and $X_{3}$ correspond to the Pectinex Ultra SP, temperature, and enzymatic treatment time, respectively. The intercept is $b_{0}$, and $b_{1}$ to $b_{33}$ are the coefficients of the polynomial equation. Analysis of variance (ANOVA) was performed to examine the main effects using a $t$-test with $95 \%$ probability. The regression coefficients and the probability values for each term in the models are shown in Table 6.

Three-dimensional (3D) response surface plots for carbendazim were drawn, as shown in Fig. 5, to evaluate the trends of the three most significant factors (Pectinex Ultra SP, temperature, and enzymatic treatment time). The conditions are shown in Table 6. The individual desirability functions were then combined into an overall desirability function $(D)$ by calculating the geometric average of different $d_{i}$ values: $\mathrm{D}=\left(\prod_{\mathrm{i}=1}^{\mathrm{n}} d_{i}\right)^{\frac{1}{n}}$, where $d_{\mathrm{i}}$ is the partial desirability function of each response and $n$ is the number of
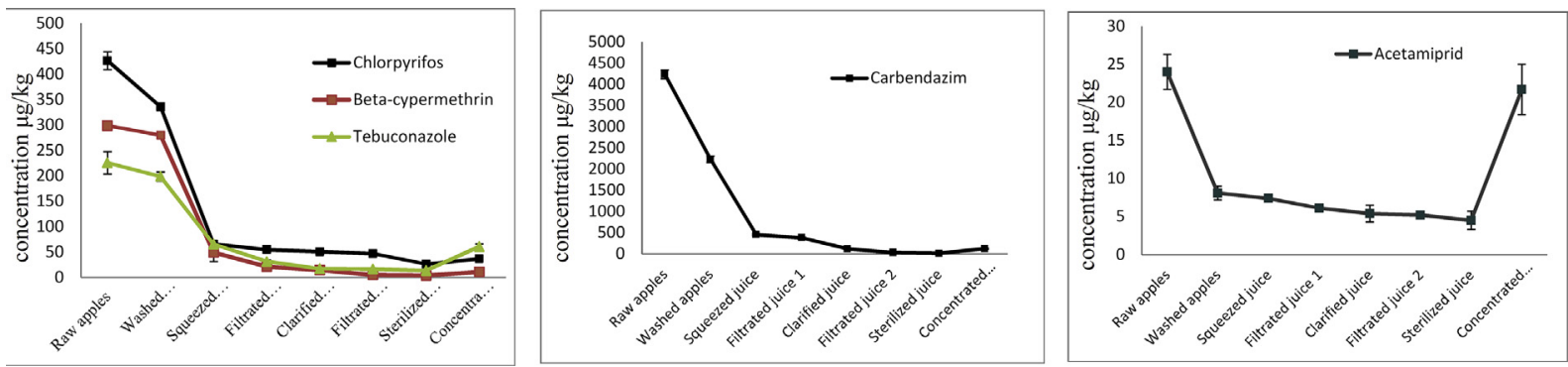

Fig. 3. Fate of the five pesticides during apple juice concentrate $(A J C)$ processing. The error bars indicate the standard errors of the measurements $(n=5)$. 

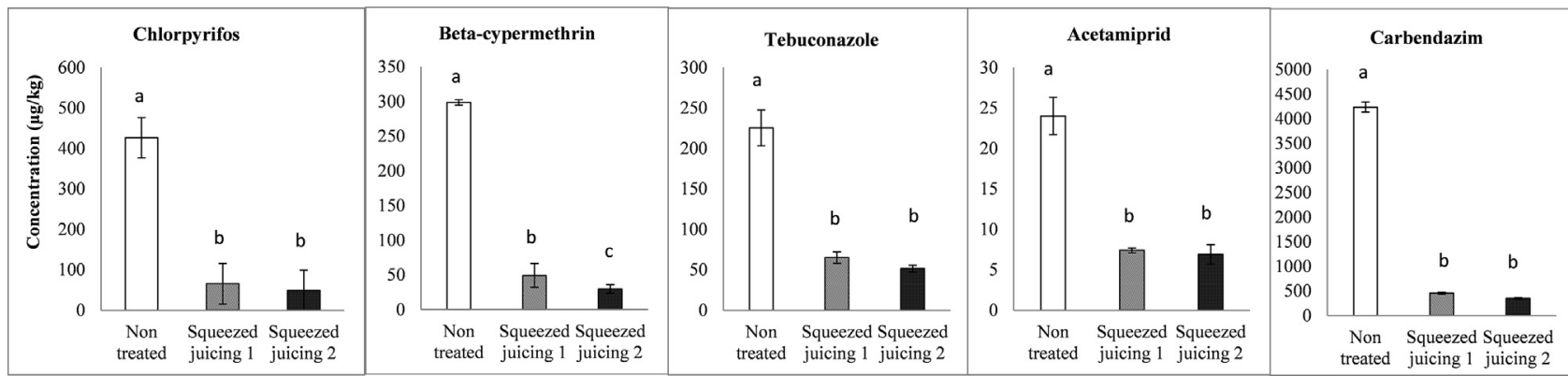

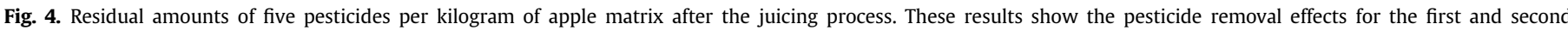
squeezings. The error bars indicate the standard errors of the measurements $(n=5)$. Data points with different letters imply significant differences $(p<0.05)$.

responses. According to the overall results calculated from the desirability function, the optimum working conditions were achieved at the following values: time, $1.5 \mathrm{~h}$; Pectinex Ultra SP, $0.1 \%$; and temperature, $50^{\circ} \mathrm{C}$.

Kaushik et al. (2009) reported that the clarifying agents tested showed no or moderate influence on the residues in wine with the exception of charcoal, which afforded the complete or almost complete elimination of residues. Nagayama (1997) observed that pectin can adsorb organophosphorus pesticides in marmalade. Similarly, a decrease in the pesticide levels in the enzymatic step might be due to the adsorption of the pesticide by the pectin. Meanwhile, the secondary filtration further reduced the residue levels of the five pesticides (Fig. 3). One important conclusion from these studies is that the elimination of pesticides during filtration and enzymatic treatment is dependent on many factors, such as the nature of the pesticide and processing techniques.

The juice was subjected to sterilization after it was clarified. In the sterilized juice, the total relative pesticide residues were $1.7-18.7 \%$ of the values in the raw apples. The residue levels of chlorpyrifos and beta-cypermethrin in the sterilized juice were decreased by $65.6 \%$ and $50.4 \%$, while the elimination of tebuconazole, acetamiprid, and carbendazim during sterilization amounted to $18.8 \%, 13.5 \%$, and $21.0 \%$, respectively. The effect of sterilization on pesticide residues is probably related to processing conditions and

Table 6

Enzymatic treatment experimental factors and levels of the CCD design of carbendazim.

\begin{tabular}{lllll}
\hline \multirow{2}{*}{ Factor } & Unit & Level & & \\
\cline { 2 - 5 } & & Low $(-1)$ & Central $(0)$ & High $(+1)$ \\
\hline (X1) Pectinex Ultra SP & $\%$ & 0.10 & 0.20 & 0.30 \\
(X2) Temperature & ${ }^{\circ} \mathrm{C}$ & 45 & 50 & 55 \\
(X3) Time & $\mathrm{h}$ & 1.0 & 1.5 & 2.0 \\
Experiments & $\mathrm{X} 1$ & $\mathrm{X} 2$ & $\mathrm{X} 3$ & Carbendazim $\left(\mu \mathrm{g} \mathrm{kg}^{-1}\right)$ \\
\hline 10 & 0.20 & 55.00 & 1.00 & 86.9 \\
12 & 0.20 & 55.00 & 2.00 & 91.4 \\
3 & 0.10 & 55.00 & 1.50 & 90.6 \\
1 & 0.10 & 45.00 & 1.50 & 85.9 \\
5 & 0.10 & 50.00 & 1.00 & 86.9 \\
11 & 0.20 & 45.00 & 2.00 & 93.8 \\
9 & 0.20 & 45.00 & 1.00 & 90.6 \\
15 & 0.20 & 50.00 & 1.50 & 91.6 \\
17 & 0.20 & 50.00 & 1.50 & 93.5 \\
14 & 0.20 & 50.00 & 1.50 & 94.3 \\
2 & 0.30 & 45.00 & 1.50 & 74.9 \\
4 & 0.30 & 55.00 & 1.50 & 85.4 \\
16 & 0.20 & 50.00 & 1.50 & 100.2 \\
7 & 0.10 & 50.00 & 2.00 & 108.7 \\
6 & 0.30 & 50.00 & 1.00 & 81.2 \\
13 & 0.20 & 50.00 & 1.50 & 107.2 \\
8 & 0.30 & 50.00 & 2.00 & 97.8 \\
\hline & & & & \\
& & & & \\
& & & & \\
& & & &
\end{tabular}

the physicochemical properties of the pesticides (Li, Jiao, et al., 2012; Li, Qu, et al., 2012). A comparison of the three types of sterilization (UHT, pasteurization, and peeling) showed that chlorpyrifos and beta-cypermethrin were thermally unstable (Fig. 6). During sterilization, these two pesticides might have been destroyed or degraded. As the UHT process is carried out in a closed system, most of the residue loss during sterilization seems to be due to the thermal instability of the pesticides. The other three pesticides are thermally stable, and their concentrations decreased only slightly. The foregoing results also indicate that the short sterilization time would not sufficiently decrease the levels of the thermally stable pesticides during the commercial processing of apple juice.

A multifunctional extraction and concentration system was used during the concentration process, and Table 4 shows the higher residue levels of these five pesticides in the AJC, although these levels were still below or close to the residue levels in whole raw apples. The residue levels of tebuconazole and acetamiprid were increased 4.5 and 4.8 times, respectively. Due to the high moisture loss during juice concentration, the increase in the residue levels from concentration is well correlated with the thermal stability of

\section{DESIGN-EXPERT Plot}

\section{Carbendazim \\ $X=A$ : Pectinex Ultra SP \\ $Y=B:$ Temperature}

\section{Actual Factor}

C: Time $=1.50$

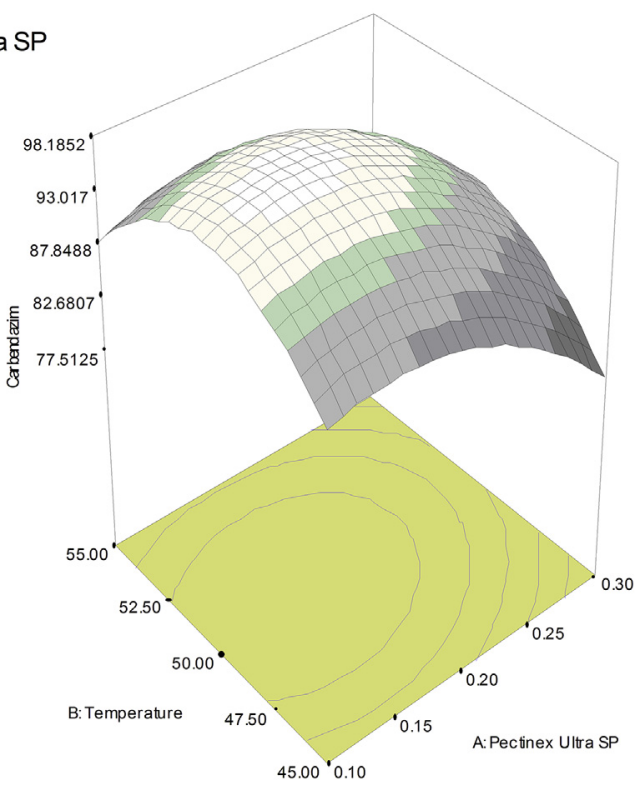

Fig. 5. Standardized main effect Pareto charts obtained from the CCD design for carbendazim, evaluating the trends of the three most significant factors (Pectinex Ultra SP, temperature, and enzymatic treatment time). 


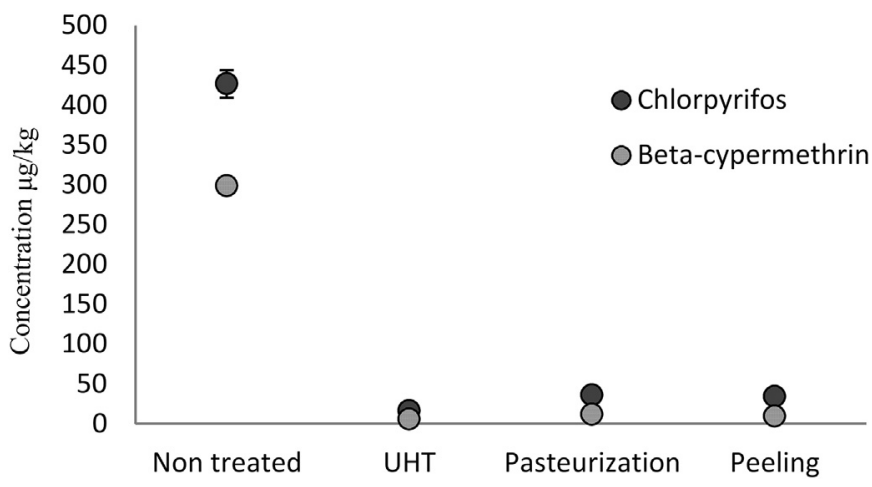

Fig. 6. Pesticide residues after the sterilization process, including the residual amounts of chlorpyrifos and beta-cypermethrin per kilogram of apple matrix. These results show the pesticide removal effects for different sterilizations processes: UHT, pasteurization, and peeling. The error bars indicate the standard errors of the measurements $(\mathrm{n}=5)$.

the pesticides. The concentrations of pesticides with high thermal stability may be increased, but the concentrations of pesticides with low thermal stability are increased only slightly or the pesticides are degraded (Li, Jiao, et al., 2012; Li, Qu, et al., 2012). Because the AJC is mainly used to produce commercial apple juice by reconstituting with water, the residue levels in commercial juice may be further decreased during the reconstitution step.

\section{Conclusion}

In the present study, the effects of simulated commercial processing on the residue levels of beta-cypermethrin, chlorpyrifos, tebuconazole, carbendazim, and acetamiprid were investigated. The PFs after each step were calculated, and the results were generally less than 1 except for concentration, which may be due to the high moisture loss that occurs during that step. In this research, for the first time, the removal process was optimized using a chemometric procedure via with a CCD combined with PFs. The results showed that the washing, squeezing, sterilization, and the time of enzymatic treatment were the key processing steps. Overall, the results will be useful for ascertaining the levels of these five common pesticides in apples and allowing the refinement of dietary risk analysis.

\section{Acknowledgments}

This work was supported financially by the National Natural Science Foundation of China (31401580 and 31301477).

\section{References}

Aguilera, A., Valverde, A., Camacho, F., Boulaid, M., \& Garcia-Fuentes, L. (2014) Household processing factors of acrinathrin, fipronil, kresoxim-methyl and pyridaben residues in green beans. Food Control, 35, 146-152.

Amvrazi, E. G., \& Albanis, T. A. (2008). Multiclass pesticide determination in olives and their processing factors in olive oil: comparison of different olive oi extraction systems. Journal of Agricultural and Food Chemistry, 56, 5700-5709.

BfR. (2010). Compilation on processing factors for pesticide residues. Available at http://www.bfr.bund.de/cm/349/bfr-compilation-of-processing-factors-forpesticide-residues.zip Accessed 20.10.11.

Burchat, C. S., Ripley, B. D., Leishman, P. D., Ritcey, G. M., Kakuda, Y., \& Stephenson, G. R. (1998). The distribution of nine pesticides between the juice and pulp of carrots and tomatoes after home processing. Food Additives \& Contaminants: Part A, 15, 61-71.

Claeys, W. L., Schmit, J. F., Bragard, C., Maghuin-Rogister, G., Pussemier, L., \& Schiffers, B (2011). Exposure of several Belgian consumer groups to pesticide residues through fresh fruit and vegetable consumption. Food Control, 22, 508-516.

Dams, R., Huestis, M. A., Lambert, W. E., \& Murphy, C. M. (2003). Matrix effect in bioanalysis of illicit drugs with LC-MS/MS: influence of ionization type, sample preparation, and biofluid. Journal of the American Society for Mass Spectrometry, $14,1290-1294$.

Dejaegher, B., \& Heyden, Y. V. (2011). Experimental designs and their recent advances in set-up, data interpretation, and analytical applications. Journal of Pharmaceutical Biomedical Analysis, 56, 141-158.

European Commission. (2009). Method validation and quality control procedures for pesticide residues analysis in food and feed. Document No. SANCO/10684/2009.

FAO/WHO. (2006). Updating the principles and methods of risk assessment: MRLs for pesticides and veterinary drugs. Rome: FAO.

Fernandez, M. J., Oliva, J., Barba, A., \& Camara, M. A. (2005). Effects of clarification and filtration processes on the removal of fungicide residues in red wines (Var. Monastrell). Journal of Agricultural and Food Chemistry, 53, 6156-6161.

Georgakopoulos, P. Zachari, R., Mataragas, M. Athanasopoulos, P., Drosinos, E. H., \& Skandamis, P. N. (2011). Optimisation of octadecyl (C18) sorbent amount in QuEChERS analytical method for the accurate organophosphorus pesticide residues determination in low-fatty baby foods with response surface methodology. Food Chemistry, 128, 536-542.

Gomez-Perez, M. L., Plaza-Bolanos, P., Romero-Gonzalez, R., Martinez-Vidal, J. L., \& Garrido-Frenich, A. (2012). Comprehensive qualitative and quantitative determination of pesticides and veterinary drugs in honey using liquid chromatography-Orbitrap high resolution mass spectrometry. Journal of Chromatography A, 1248, 130-138.

Han, Y., Li, W., Dong, F., Xu, J., Liu, X., Li, Y., et al. (2013). The behavior of chlorpyrifos and its metabolite 3,5,6-trichloro-2-pyridinol in tomatoes during home canning. Food Control, 31, 560-565.

Han, Y., Xu, J., Dong, F., Dong, F., Li, W., Liu, X., et al. (2013). The fate of spirotetramat and its metabolite spirotetramat-enol in apple sample s during apple cider processing. Food Control, 34, 283-290.

Holland, P. T., Hamilton, D., Ohlin, B., \& Skidmore, M. W. (1994). Effects of storage and processing on pesticide residues in the plant products (technical report). Pure and Applied Chemistry, 66, 335-356.

Kaushik, G., Satya, S., \& Naik, S. N. (2009). Food processing a tool to pesticide residue dissipation-A review. Food Research International, 42, 26-40.

Khodadousta, S., Ghaedia, M., \& Hadjmohammadib, M. R. (2013). Dispersive nano solid material-ultrasound assisted microextraction as a novel method for extraction and determination of bendiocarb and promecarb: response surface methodology. Talanta, 116, 637-646.

Kong, Z., Dong, F., Xu, J., Liu, X., Zhang, C., Li, J., et al. (2012). Determination of difenoconazole residue in tomato during home canning by UPLC-MS/MS. Food Control, 23, 542-546.

Kong, Z., Shan, W., Dong, F., Liu, X., Xu, J., Li, M., et al. (2012). Effect of home processing on the distribution and reduction of pesticide residues in apples. Food Additives \& Contaminants: Part A, 29, 1280-1287.

Li, Y., Jiao, B., Zhao, Q., Wang, C., Gong, Y., Zhang, Y., et al. (2012). Effect of commercial processing on pesticide residues in orange products. European Food Research and Technology, 234, 449-456.

Ling, Y., Wang, H., Yong, W., Zhang, F., Sun, L., Yang, M. L., et al. (2011). The effects of washing and cooking on chlorpyrifos and its toxic metabolites in vegetables. Food Control, 22, 54-58.

Li, J., Qiu, H., Cai, Y., \& Li, S. (2012). Export situation of Chinese apple products, restrict element and countermeasure analysis. World Agriculture, 5, 73-78 (in Chinese).

Lopez-Fernandez, O., Rial-Otero, R., \& Simal-Gandara, J. (2013). Factors governing the removal of mancozeb residues from lettuces with washing solutions. Food Control, 34, 530-538.

Martin, L., Mezcua, M., Ferrer, C., Gil Garcia, M. D., Malato, O., \& FernandezAlba, A. R. (2013). Prediction of the processing factor for pesticides in apple juice by principal component analysis and multiple linear regression. Food Additives \& Contaminants: Part A, 30, 466-476.

Nagayama, T. (1997). Decrease in organic solvent extractable ethion by grapefruit pectin during processing. Journal of Agricultural and Food Chemistry, 45, 4856-4860.

OECD. (2008). OECD guideline for the testing of chemicals. Magnitude of the pesticide residues in processed commodities. NO. 508.

Oliva, J., Paya, P., Camara, M. A., \& Barba, A. (2007). Removal of famoxadone, fluquinconazole and trifloxystrobin residues in red wines: effects of clarification and filtration processes. Journal of Environmental Science and Health Part B: Pesticides Food Contaminants and Agricultural Wastes, 42, 775-781.

Paiga, P., Morais, S., Oliva-Teles, T., Correia, M., Delerue-Matos, C., Duarte, S. C., et al (2012). Extraction of ochratoxin A in bread samples by the QuEChERS methodology. Food Chemistry, 135, 2522-2528.

Perez-Burgos, R., Grzelak, E. M., Gokce, G., Saurina, J., Barbosa, J., \& Barron, D. (2012). Quechers methodologies as an alternative to solid phase extraction (SPE) for the determination and characterization of residues of cephalosporins in beef muscle using LC-MS/MS. Journal of Chromatography B, 899, 57-65.

Pirsaheb, M., Fattahi, N., Pourhaghighat, S., Shamsipur, M., \& Sharafi, K. (2014). Simultaneous determination of imidacloprid and diazinon in apple and pear samples using sonication and dispersive liquid-liquid microextraction. LWT Food Science and Technology, 60, 1-7.

Ren, A., Qiu, X., Jin, L., Ma, J., Li, Z., Zhang, L., et al. (2011). Association of selected persistent organic pollutants in the placenta with the risk of neural tube defects. Proceedings of the National Academy of Sciences, 108, 12770-12775.

Timme, G., \& Walz-Tylla, B. (2004). Effects of food preparation and processing on pesticide residues in commodities of plant origin. Pesticide Residues in Food and Drinking Water, 121-148.

Zhang, C., Zhao, H., Wu, M., Hu, X., Cai, X., Ping, L., et al. (2012). Simultaneous determination of procymidone, pyridaben and beta-cypermethrin residues in Tea solution by GC-ECD. Journal of Chromatographic Science, 50, 940-944. 